\title{
Control of sawtooth via ECRH on EAST tokamak
}

Yi Yuan, Liqun Hu, Liqing Xu', Xiaoguang Wang, Xiaojie Wang, Handong Xu, Zhengping Luo, Kaiyun Chen, Shiyao Lin, Yanmin Duan, Pengxiang Chang, Hailin Zhao, Kaiyang He, and Yunfeng Liang

Citation: Physics of Plasmas 23, 062503 (2016); doi: 10.1063/1.4953605

View online: http://dx.doi.org/10.1063/1.4953605

View Table of Contents: http://aip.scitation.org/toc/php/23/6

Published by the American Institute of Physics

\section{Articles you may be interested in}

Lower hybrid current drive experiments with different launched wave frequencies in the EAST tokamak

Physics of Plasmas 23, 102512 (2016); 10.1063/1.4965904

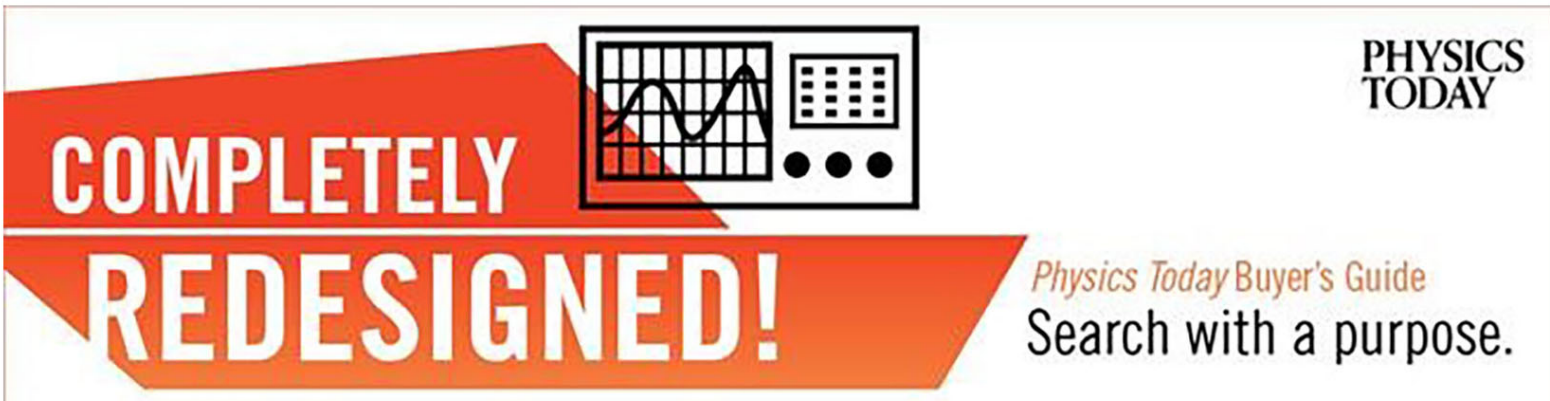




\title{
Control of sawtooth via ECRH on EAST tokamak
}

\author{
Yi Yuan, ${ }^{1,2}$ Liqun Hu, ${ }^{1}$ Liqing $\mathrm{Xu},{ }^{1, a)}$ Xiaoguang Wang, ${ }^{3}$ Xiaojie Wang, ${ }^{1}$ Handong $\mathrm{Xu},{ }^{1}$ \\ Zhengping Luo, ${ }^{1}$ Kaiyun Chen, ${ }^{1}$ Shiyao Lin, ${ }^{1}$ Yanmin Duan, ${ }^{1}$ Pengxiang Chang, \\ Hailin Zhao, ${ }^{1}$ Kaiyang $\mathrm{He},{ }^{1}$ and Yunfeng Liang ${ }^{1}$ \\ ${ }_{1}^{1}$ Institute of Plasma Physics, Chinese Academy of Sciences, Hefei 230031, China \\ ${ }^{2}$ University of Science and Technology of China, Hefei 230031, China \\ ${ }^{3}$ Center for Fusion Energy Science and Technology, Chinese Academy of Engineering Physics, \\ Beijing 100000, China
}

(Received 15 March 2016; accepted 27 May 2016; published online 9 June 2016)

Localized electron heating produced by electron cyclotron resonant heating (ECRH) system has been proven to be powerful tools for controlling sawtooth instabilities, because such system allows to directly modify the local plasma parameters that determine the evolution of sawtooth periods. In this paper, we present the experimental results carried out on experimental advanced superconducting tokamak (EAST) with regard to sawtooth period control via ECRH. The electron cyclotron heating system on EAST was capable of inject electron cyclotron wave toward certain locations inside or outside $\mathrm{q}=1$ magnetic surface on the poloidal cross section, which renders us able to investigate the evolution of sawtooth period against the ECRH deposition position. It is found that when ECRH deposition position is inside the $\mathrm{q}=1$ surface, the sawtooth oscillation is destabilized (characterized by reduced sawtooth period). So far, inside the $\mathrm{q}=1$ surface, there are not enough EAST experiment data that can reveal more detailed information about the relation between ECRH deposition position and sawtooth period. When ECRH deposition is outside the $\mathrm{q}=1$ surface, the sawtooth oscillation is stabilized (characterized by prolonged sawtooth period), and the sawtooth periods gradually decrease as ECRH deposition position sweeps away from $\mathrm{q}=1$ surface. The sawtooth periods reach maximum when ECRH deposition position falls around $q=1$ surface. The magnetic shear at $q=1$ surface is calculated to offer insights for the temporal evolution of sawtooth. The result has been found consistent with the Porcelli model. Published by AIP Publishing.

[http://dx.doi.org/10.1063/1.4953605]

\section{INTRODUCTION}

Sawtooth oscillation, ${ }^{1}$ characterized by periodic relaxations of the plasma temperature, density, and other plasma parameters in the central region of a tokamak plasma, was first observed on Sphere Torus tokamak on soft-X ray (SXR) diagnostic signal in 1974. Since then, it has been observed on almost all the large tokamaks. The sawtooth cycle consists of a quiescent period, during which the plasma density and the temperature increase, therefore creating a peaked density and temperature profile. Then, it is followed by a rapid drop (sawtooth crash), which is usually thought to be triggered by destabilization of an internal kink mode with poloidal number $\mathrm{m}=1$ and toroidal number $\mathrm{n}=1$.

Sawtooth activity plays an important role in determining plasma profiles and plasma performance. In particular, it has been shown that long sawtooth periods can have undesirable consequences, such as the creation of seed magnetic island capable of triggering neoclassical tearing modes (NTMs)., ${ }^{2,3}$

The NTMs can seriously degrade plasma confinement and sometimes even cause disruption. JET experiment has confirmed that the stabilizing effects of fusion-born energetic $\alpha$ particles would result in monster sawtooth, which is loosely defined as sawtooth with periods longer than the energy confinement time. ${ }^{4}$ Consequently, in recent years,

\footnotetext{
${ }^{a)}$ Email: lqxu@ipp.cas.cn
}

great many efforts have been made to deliberately destabilize sawtooth, yet it remains an important unsolved issue for the future ITER operations. In addition, the sawtooth activity has been found to facilitate the removal of impurities from the plasma core region, which is highly desirable effects considering the presence of helium ashes in the future burning plasma. Therefore, the objective of sawtooth control experiment is to identify various methods to destabilize sawtooth in an attempt to avoid seeding NTMs whilst keeping the benefits of small, frequent sawtooth to remove core impurity accumulation.

Among the possible auxiliary plasma heating systems, localized electron cyclotron resonant heating (ECRH) and current drive (ECCD) have been proven particularly effective for this purpose. Localized ECRH/ECCD makes it possible to directly modify local plasma profiles such as the plasma current profile and consequently safety factor q profile. These profiles play an important role in the sawtooth behavior. $^{5-10}$ According to a widely accepted sawtooth model proposed by Porcelli, ${ }^{11}$ sawtooth crashes are triggered if magnetic shear $s_{1}=r_{1} d q / d r$ at the $q=1$ surface exceeds a certain critical value $s_{1, \text { crit }}$, where $s_{1, \text { crit }}$, defined at the same $\mathrm{q}=1$ magnetic surface, is determined by ion/electron temperature, ion Larmor radius, electron/ion diamagnetic frequencies, and the collisionality regime. By changing the poloidal and toroidal injection angle of ECRH system within one single shot or between different shots, we can modify 
the ECRH deposition position. Therefore, the relation between the sawtooth periods and the heat deposition position can be investigated. A long pulse ECRH system has been installed and successfully operating in 2015 spring campaign, which allows to conduct such experiments on experimental advanced superconducting tokamak (EAST).

The primary goal of this paper is to present the recent experimental results on EAST to corroborate the validity of using ECRH for sawtooth control. The rest of the paper is organized as follows: various profiles, their evolution, and a model of sawtooth crash are presented in Section II, experimental setup is presented in Section III, the experimental results and discussion are presented in Section IV, and the conclusion is presented in Section V.

\section{SAWTOOTH PHYSICS UNDER LOCALIZED ECRH}

\section{A. Localized heating effect of ECRH}

$10 \mathrm{~ms}$ after ECRH is injected into the plasma, and the localized heating effect of electron cyclotron wave is clearly demonstrated in the electron temperature profiles from electron cyclotron emission (ECE) diagnostic data (shot 54424, Fig. 1(a)). The electron temperature variation profile is then mapped at Normalized poloidal flux coordinate $\rho$. It is found that the peaked temperature variation profile matches very well with the ECRH power deposition profile calculated by Toray ray-tracing code (see Fig. 1(b)).

Local temperature rise would decrease plasma resistivity ( $\left.\eta \sim T^{-\frac{3}{2}}\right)$ causing current density profile to change. Disturbed current density profile $\mathrm{j}(\mathrm{r})$ consequently means a disturbed plasma current profile I(r), which would lead to a perturbed safety factor profile $q(r)=\frac{2 \pi r^{2} B_{\phi 0}}{\mu_{0} R I(r)}$. The perturbed safety profile changes magnetic shear $\mathrm{s}_{1}=\mathrm{r}_{1} \mathrm{dq} / \mathrm{dr}$ at $\mathrm{q}=1$ surface (see Fig. 1(c)).

Here, sawtooth inversion radius is approximately regarded as the $\mathrm{q}=1$ surface. It is determined by using ECE diagnostic or Soft-X ray (SXR) diagnostic data. The safety factor q profile is calculated from Equilibrium FITting algorithm (EFIT) using magnetic probe data and the previously
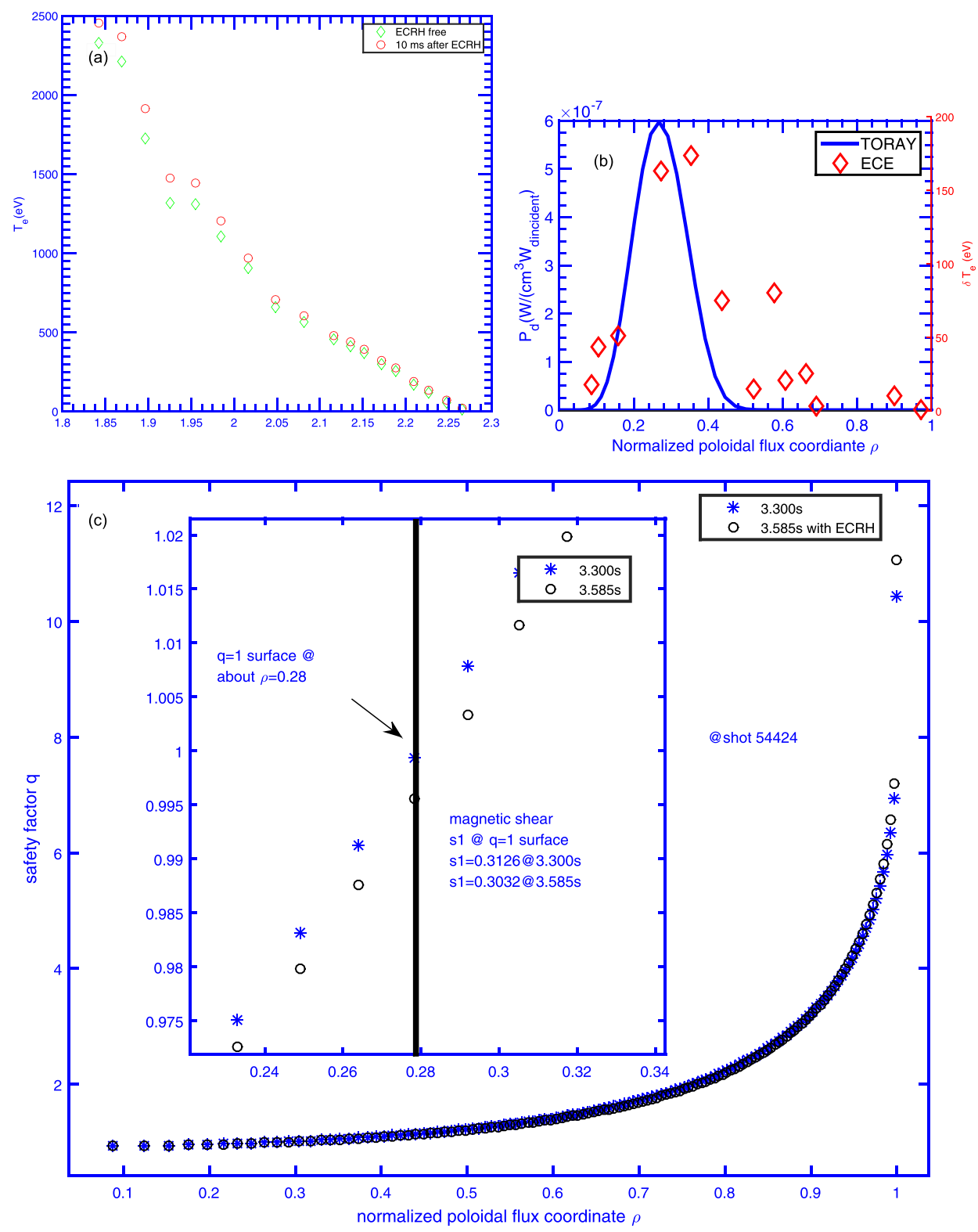

FIG. 1. (a) Electron temperature profile before and after ECRH injection from electron cyclotron emission (ECE) diagnostic data. (b) ECRH deposition location calculated by TORAY ray tracing code. The electron temperature variation is mapped into the same normalized poloidal flux coordinate. The deposited heat flux profile corresponds with the electron temperature variation profile at normalized poloidal flux coordinate $\rho=0.2679$ ( $1.9 \mathrm{~m}$ of large radius). (c) The safety factor profiles at $3.300 \mathrm{~s}$ and $3.585 \mathrm{~s}$ (shot 54424). $\mathrm{q}=1$ surface is at about $\rho=0.28$ of normalized poloidal flux coordinate. The corresponding magnetic shear at $q=1$ surface, $s 1$, is, respectively, 0.3126 and 0.3032 . 


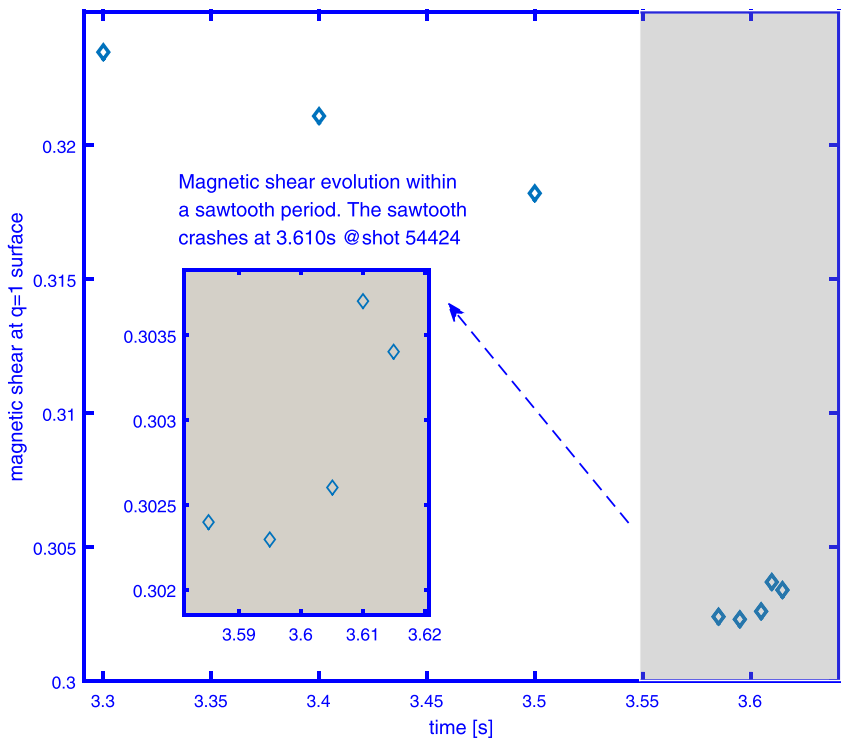

FIG. 2. Magnetic shear at $\mathrm{q}=1$ surface, $\mathrm{s} 1$, at $3.300 \mathrm{~s} 3.400 \mathrm{~s} 3.500 \mathrm{~s} 3.585 \mathrm{~s}$ $3.595 \mathrm{~s} 3.605 \mathrm{~s} 3.610 \mathrm{~s}$, and $3.615 \mathrm{~s}$. The time domain, when ECRH was injected after $3.55 \mathrm{~s}$, is illustrated with gray shading. Time points $3.585 \mathrm{~s}$ $3.595 \mathrm{~s} 3.605 \mathrm{~s} 3.610 \mathrm{~s}$, and $3.615 \mathrm{~s}$ are within a single sawtooth period. Sawtooth crashes at $3.610 \mathrm{~s}$.

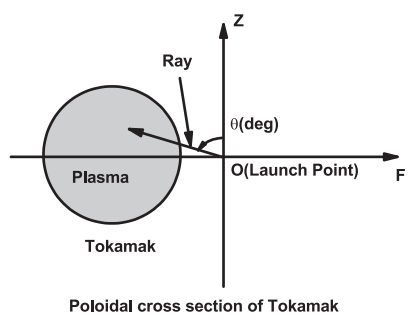

(a)

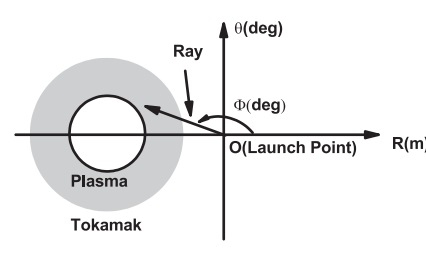

FIG. 3. The launcher sweep range: (a) poloidal angle $\theta\left(\theta, 65^{\circ}-95^{\circ}\right)$ and (b) toroidal angle $\phi\left(\phi, 165^{\circ}-205^{\circ}\right)$, respectively. mentioned $\mathrm{q}=1$ surface as a condition for convergence. Normalized poloidal flux coordinate $\rho$ is defined as $\rho=\sqrt{\Psi}$, where $\Psi$ is the poloidal flux.

\section{B. Model of sawtooth period}

According to the sawtooth model first proposed by Porcelli et al. ${ }^{11}$ and then modified in Tokamak à Configuration Variable (TCV) experiments,${ }^{8}$ the triggering condition of $1 / 1$ internal kink mode that induces sawtooth crash can be written in the form

$$
s_{1}>s_{1, \text { crit }}
$$

Here, $\mathrm{s}_{1, \text { crit }}$, the critical shear at $\mathrm{q}=1$ surface, is given by the different expressions depending on whether the internal kink mode becomes unstable in the resistive or ion-kinetic regime. ${ }^{8}$

Using the safety factor profile provided by EFIT, two series of magnetic shear at $\mathrm{q}=1$ surface is calculated at shot 54424 . One at a time interval of $0.1 \mathrm{~s}(3.300 \mathrm{~s}, 3.400 \mathrm{~s}$, and $3.500 \mathrm{~s})$, and the other with a much shorter time scale $(3.585 \mathrm{~s}$, $3.595 \mathrm{~s}, 3.605 \mathrm{~s}, 3.610 \mathrm{~s}$, and $3.615 \mathrm{~s}$ ). Note that time points $3.585 \mathrm{~s}, 3.595 \mathrm{~s}, 3.605 \mathrm{~s}, 3.610 \mathrm{~s}$, and $3.615 \mathrm{~s}$ are within a sawtooth period. ECRH was injected after $3.55 \mathrm{~s}$ (see Fig. 2).

Comparing magnetic shear before and after ECRH injection, it is obvious that magnetic shear is lower during ECRH phase. Within a sawtooth period $(3.585 \mathrm{~s}, 3.595 \mathrm{~s}, 3.605 \mathrm{~s}$, $3.610 \mathrm{~s}$, and $3.615 \mathrm{~s}$ ), it is found that the magnetic shear $\mathrm{s}_{1}$ first gradually increases $(3.585 \mathrm{~s}, 3.595 \mathrm{~s}$, and $3.605 \mathrm{~s})$ until it reaches a certain maximum value at about $3.610 \mathrm{~s}$ and then it drops at $3.615 \mathrm{~s}$. The result is consistent with the Porcelli model.

\section{EXPERIMENTAL SET-UP}

The experimental advanced superconducting tokamak $\left(\right.$ EAST) ${ }^{12}$ is the first full superconducting tokamak with advanced configuration in the world. Its purpose is to explore

EAST shot 54405
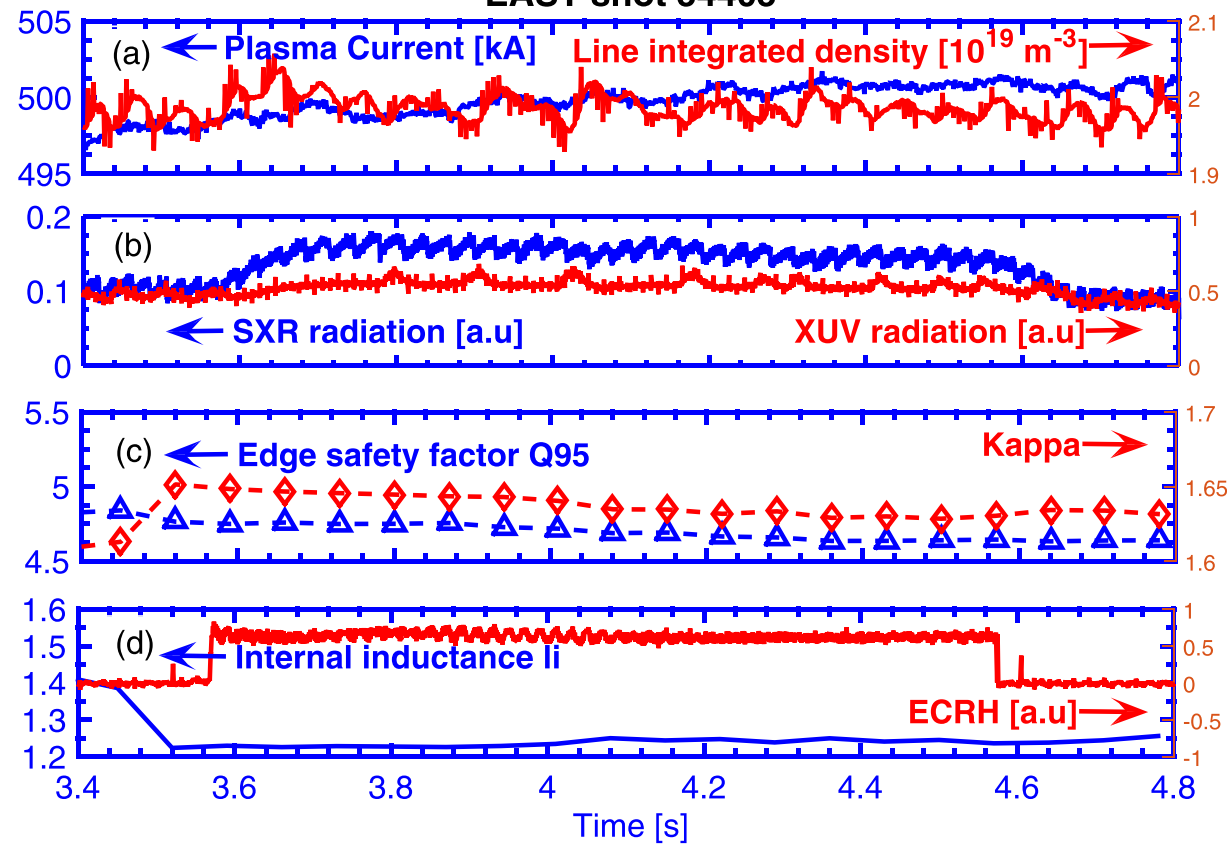

FIG. 4. Plasma conditions of EAST shot 54405. Temporal evolution of (a) plasma current (blue line) and line integrated density (red line) from hydrogen cyanide interferometer, (b) soft-X ray radiation at the plasma center (blue line) and extreme ultraviolet radiation at the plasma center (red line), (c) edge safety factor Q95 (blue line) from EFIT and the plasma triangularity Kappa (red line) from EFIT, and (d) plasma internal inductance li (blue line) from EFIT and voltage of ECRH gyrotron (red line). 
the scientific and technological basis for the next generation tokamak reactors. EAST has a major radius of $\mathrm{R}=1.75 \mathrm{~m}$, minor radius of $\mathrm{a}=0.4 \mathrm{~m}$, typical aspect ratio of 4.25 , an elongation of 1.2-2, the typical toroidal magnetic field (TF) 1.5-3 T, and the plasma current Ip up to $1 \mathrm{MA}$. The device can be operated in multi-configurations including lower single null (LSN), upper single null (USN), and double null. To obtain high performance plasma in EAST, some auxiliary heating and current drive methods have been developed, including electron cyclotron resonant heating (ECRH) and neutral beam injection (NBI) system. There are many diagnostics on EAST to extract basic plasma parameters, such as electron temperature, electron density, and current density profile. The main diagnostics involved in analyzing the magnetohydrodynamic (MHD) instabilities in this article is soft X-ray
(SXR) imaging diagnostic and Mirnov coils. The high spatial and temporal resolution soft X-ray (SXR) imaging diagnostic, with two up-down symmetrical horizontal arrays and one vertical array, can be used to observe MHD instabilities on the poloidal cross-section. Mirnov coils mounted poloidally and toroidally can give the mode number of the MHD instability.

In this paper, all the discharges involved are heated by NBI and ECRH. EC wave is overlaid on NBI in order to investigate the effects of ECRH on sawtooth period, while using NBI as background. The long pulse ECRH system on EAST has been successfully installed and first EC wave has been injected into plasma during the 2015 spring campaign. The system is designed to have four $140 \mathrm{GHz}$ gyrotron systems. Currently, only the No. 1 and No. 2 gyrotron systems have been installed. In the initial commissioning, a series of parameters of $1 \mathrm{MW} 1 \mathrm{~s}$,
$54426 @$ EAST
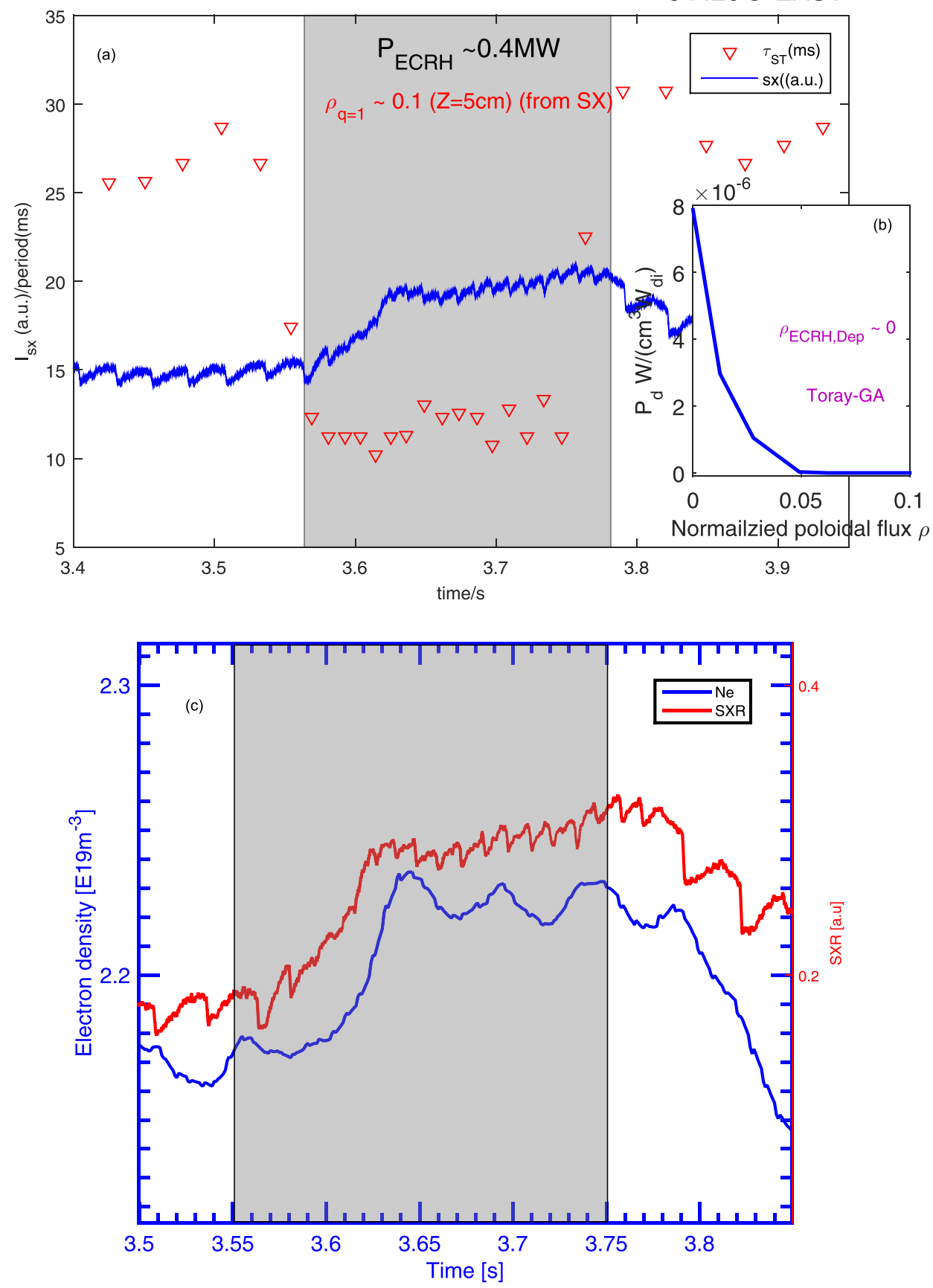

FIG. 5. (a) Temporal evolvement of sawtooth period of shot 54426; the time domain when ECRH was injected was illustrated with shading; triangular represents the sawtooth period; and sawtooth was destabilized (characterized by reduced period) due to ECRH. (b) ECRH deposition position calculated by TORAY-GA ray-tracing code. (c) Time trace of SXR signal and electron density of shot 54426 . The time domain, when ECRH was injected, is illustrated with shading. At $3.55 \mathrm{~s}-3.65 \mathrm{~s}$, sawtooth behavior is dominated by a density increase. Then, at $3.65 \mathrm{~s}-3.75 \mathrm{~s}$, sawtooth behavior is dominated by heating effects of EC wave. 
$900 \mathrm{~kW} 10 \mathrm{~s}, 800 \mathrm{~kW} 95 \mathrm{~s}$, and $650 \mathrm{~kW} 753 \mathrm{~s}$ have been demonstrated successfully on the No. 1 gyrotron system. When it reaches its full capacity, each gyrotron is expected to deliver a maximum power of $1 \mathrm{MW}$ and be operated at $100 \mathrm{~s}-1000 \mathrm{~s}$ pulse lengths. The RF power transmitted through four evacuated corrugated waveguides will be injected into plasma from the low field side. A launcher with four independent channels was developed for EAST, with the four channels designed in a symmetrical arrangement relative to equatorial plain as well as the
M port of EAST. Each channel uses a fixed focus mirror and a steering plain mirror, and a section of stainless steel waveguide is adopted to transmit millimeter waves to the focus mirror in vacuum of EAST. The launcher parameters were designed as follows: the poloidal sweep range is $65^{\circ}-95^{\circ}$, and the toroidal range is $165^{\circ}-205^{\circ}$. In addition, the definition of the poloidal angle $\theta$ and toroidal angle $\phi$ is consistent with the corresponding angles defined in TORAY ray tracing code (see Fig. 3 for toroidal angel $\phi$ and poloidal angle $\theta$, respectively). Therefore,
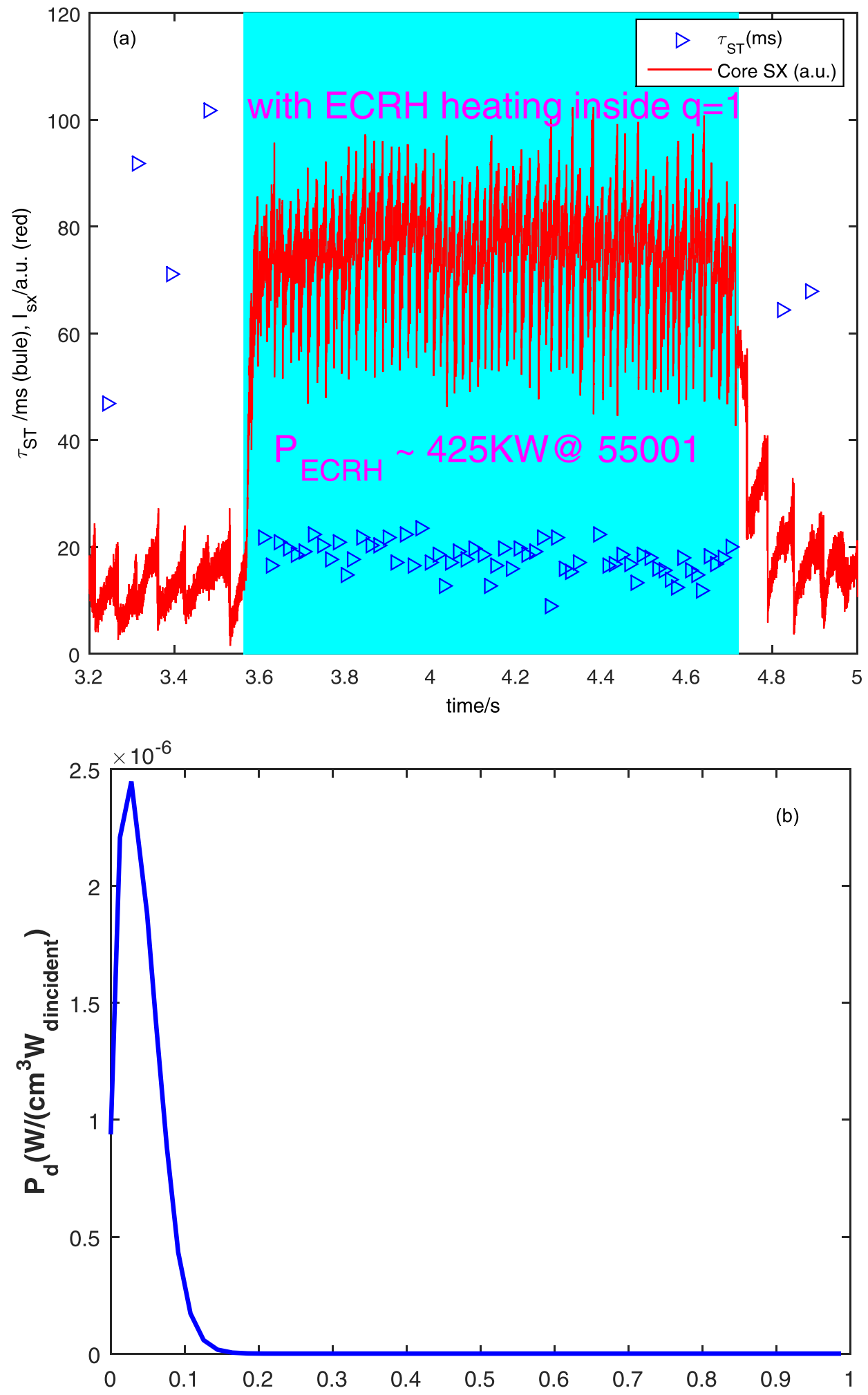

FIG. 6. (a) Temporal evolvement of sawtooth period of shot 55001; the time domain, when ECRH was injected, is illustrated with shading; triangular represents the sawtooth period; and sawtooth is destabilized (characterized by reduced sawtooth period) due to ECRH. (b) ECRH deposition position calculated by TORAY-GA ray-tracing code. 
the system allows us to change these injection angles between different plasma discharges to investigate the effects of different ECRH deposition positions on sawtooth periods. In this paper, we use TORAY ray tracing code to specify the heat deposition of ECRH. The TORAY ray tracing code computes contributions to electron cyclotron heating $(\mathrm{ECH})$ and $\mathrm{RF}$ current-drive (ECCD) sources. To run TORAY ray tracing code, we need electron temperature profile, electron density profile provided by Thompson scattering diagnostic, EC wave injection angle $\theta$, $\phi$, and equilibrium EQDSK file generated from Equilibrium FITting algorithm (EFIT). ${ }^{13}$

The reference plasma discharge (see Fig. 4) has the following parameters: $\mathrm{LSN}, \mathrm{I}_{\mathrm{p}}=500 \mathrm{kA}, \mathrm{B}_{\mathrm{t}}=2.3 \mathrm{~T}$, lineaveraged density $\mathrm{n}_{\mathrm{el}}=2.0 \times 10^{19} \mathrm{~m}^{-3}$, and $\mathrm{q}_{95}=4.840$. For shots 54401-54411, the ECRH pulses last $1 \mathrm{~s}$. For shots 54420-54428, the ECRH pulses last $0.2 \mathrm{~s}$. The injection power of EC wave is $420 \mathrm{~kW}$. The NBI power is $2 \mathrm{MW}$.

\section{RESULTS AND DISCUSSION}

In the 2015 spring campaign, multiple sawtooth discharges have been acquired by sweeping the poloidal injection angle $\theta$ between different shots while retaining the toroidal injection angle $\phi$ relatively stable. The results shows that sawtooth demonstrates different behaviors with regard to the ECRH deposition position against $\mathrm{q}=1$ surface.

\section{A. ECRH deposition inside $q=1$ surface}

For the scenario where ECRH is injected inside the $\mathrm{q}=1$ surface, the toroidal angle $\phi$ was kept at $180^{\circ}-200^{\circ}$, while the poloidal angle $\theta$ sweeps from $70^{\circ}$ to $80^{\circ}$. During the experiment, only a few such shots prove useful for our purpose (shots 54426 and 55001). For shot 54426, poloidal angle $\theta$ is $75^{\circ}$ and toroidal angle $\phi$ is $180^{\circ}$. For shot 55001, poloidal angle $\theta$ is $80^{\circ}$ and toroidal angle $\phi$ is $200^{\circ}$. In these shots, sawtooth was destabilized (characterized by reduced sawtooth period) after ECRH injection (Figs. 5 and 6). So far, there are not enough EAST experiment data that can reveal more detailed information about the relation between ECRH deposition position and sawtooth period inside the $q=1$ surface. The relation will be investigated in the future EAST sawtooth experiments.

\section{B. ECRH deposition outside $q=1$ surface}

For shots 54402, 54404, 54405, and 54406, the toroidal angle was kept at $180^{\circ}$, while the poloidal angle sweeps from $70^{\circ}$ to $93^{\circ}$. The ECRH deposition position lies outside $\mathrm{q}=1$ surface. The sawtooth periods are very sensitive to ECRH, as shown in Fig. 7.

For the scenario where ECRH is injected outside the $q=1$ surface (Fig. 7, shot 54405), sawtooth is stabilized (characterized by the prolonged sawtooth period). In addition, by investigating between different shots, it is found that the sawtooth periods reach maximum when the ECRH deposition position falls around $\mathrm{q}=1$ surface and then gradually diminish as ECRH deposition position sweeps away from $q=1$ surface (Fig. 8).

\section{CONCLUSION}

The effects of localized ECRH on the sawtooth period have been explored with a sequence of discharges on EAST

54405@EAST

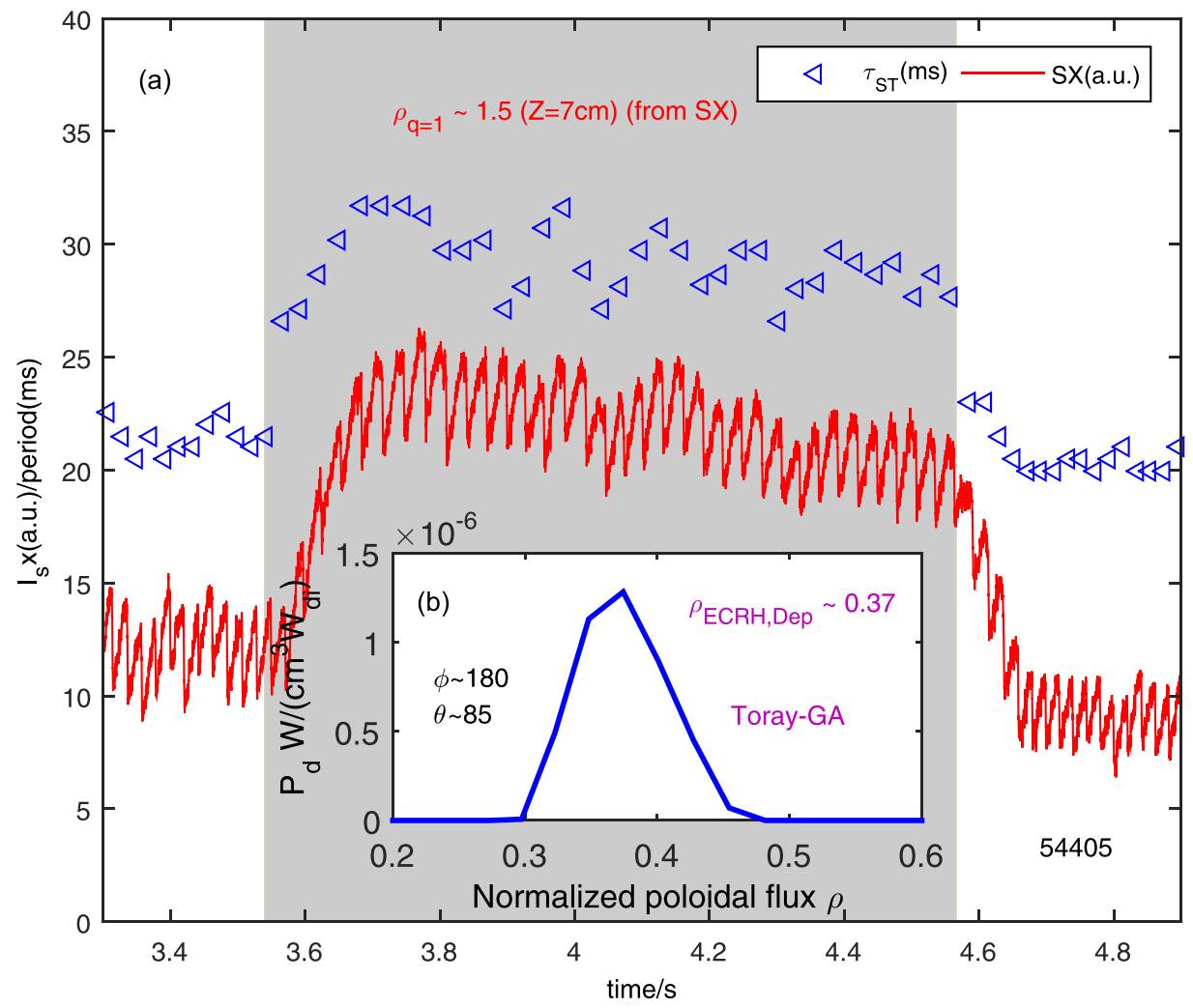

FIG. 7. (a) Temporal evolvement of sawtooth period of shot 54405; the time domain, when ECRH was injected, is illustrated with shading; triangular represents the sawtooth period; and sawtooth is stabilized (characterized by prolonged period) due to ECRH. (b) ECRH deposition position calculated by TORAY-GA ray-tracing code 


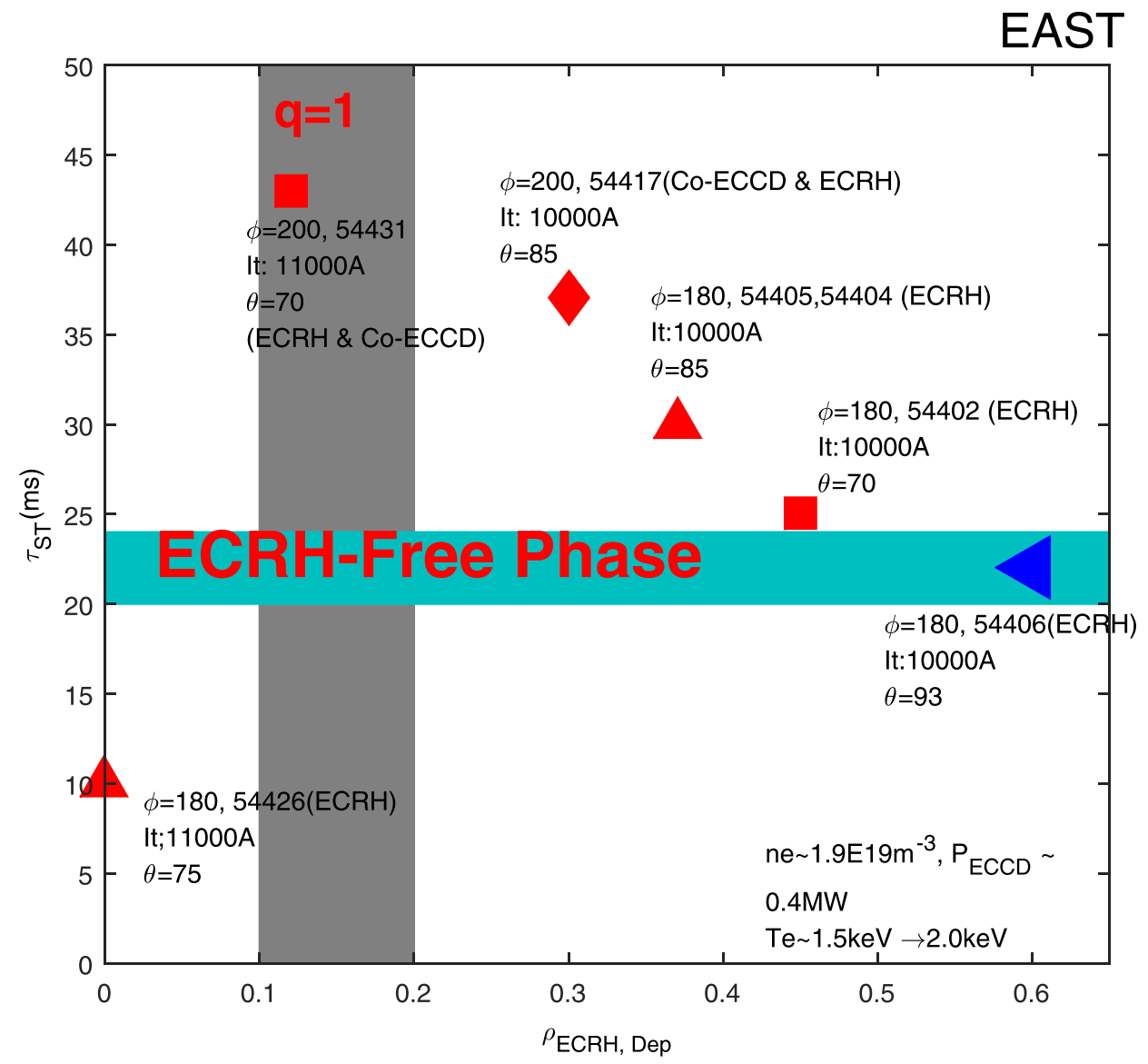

FIG. 8. The $\mathrm{x}$-coordinate is heat deposition position; the $y$-coordinate is sawtooth period; the shading area is where $\mathrm{q}=1$ surface lies. As ECRH deposition gradually moves away from $\mathrm{q}=1$ surface, the sawtooth period diminishes. Sawtooth period reaches its maximum at about $\mathrm{q}=1$ surface.

during the 2015 spring campaign. By changing the injection angle of EC wave launcher, both toroidal angle $\phi$ and poloidal angle $\theta$, respectively, between different discharges, the ECRH deposition is swept across the poloidal cross section. TORAY ray tracing code can calculate the corresponding heat deposition locations. The relation between heat deposition location and sawtooth period is then investigated. It is found that sawtooth periods demonstrate different behaviors depending on the heating location with regard to $q=1$ surface. Inside $q=1$ surface, the sawtooth period is decreased. Outside the $\mathrm{q}=1$ surface, within a single discharge, sawtooth periods increase after ECRH. Comparing with different discharges, it is found that sawtooth periods gradually decrease as the heating location sweeps away from $\mathrm{q}=1$ surface, yet they still increase with respect to pre-ECRH phase. Sawtooth periods reach maximum around $\mathrm{q}=1$ surface.

These experimental results corroborate the validity of using ECRH for sawtooth control and provide useful references for the future ECRH sawtooth control experiments on EAST. To destablize sawtooth, the heating position should be localized inside $\mathrm{q}=1$ magnetic surface. To achieve longer sawtooth periods for the benefit of facilitating the removal of core impurities, ECRH location should be closer to the $\mathrm{q}=1$ magnetic surface from outside the $\mathrm{q}=1$ surface.

\section{ACKNOWLEDGMENTS}

This work was partially supported by the JSPS-NRFNSFCA3 Foresight Program in the field of Plasma Physics (NSFC) under Grant No. 11261140328, the National Magnetic
Confinement Fusion Science Program of China under Contract No. 2013GB106003B, the National Magnetic Confinement Fusion Science Program of China (Grant No. 2014GB124006), and the National Magnetic Confinement Fusion Science Program of China under Contract No. 2012GB103000.

${ }^{1}$ S. Von Goeler, W. Stodiek, and N. Sauthoff, Phys. Rev. Lett. 33, 1201 (1974).

${ }^{2}$ G. P. Canal, B. P. Duval, F. Felici, T. P. Goodman, J. P. Graves, A. Pochelon, H. Reimerdes, O. Sauter, D. Testa, and T. Team, Nucl. Fusion 53, 113026 (2013).

${ }^{3}$ O. Sauter, E. Westerhof, M. L. Mayoral, B. Alper, P. a. Belo, R. J. Buttery, A. Gondhalekar, T. Hellsten, T. C. Hender, D. F. Howell, T. Johnson, P. Lamalle, M. J. Mantsinen, F. Milani, M. F. F. Nave, F. Nguyen, A. L. Pecquet, S. D. Pinches, S. Podda, and J. Rapp, Phys. Rev. Lett. 88, 105001 (2002).

${ }^{4}$ M. J. Mantsinen, M. L. Mayoral, V. G. Kiptily, S. E. Sharapov, B. Alper, A. Bickley, M. de Baar, L. G. Eriksson, A. Gondhalekar, T. Hellsten, K. Lawson, F. Nguyen, J. M. Noterdaeme, E. Righi, A. A. Tuccillo, and M. Zerbini, Phys. Rev. Lett. 88, 105002 (2002).

${ }^{5}$ S. Nowak, P. Buratti, S. Cirant, B. Esposito, G. Granucci, E. Lazzaro, D. Marocco, C. Sozzi, A. A. Tuccillo, E. Alessi, D. Frigione, G. Pucella, A. Romano, O. Tudisco, and F. T. U. Team, Nucl. Fusion 54, 033003 (2014). ${ }^{6}$ S. Cirant, A. Airoldi, L. Bertalot, G. Bracco, A. Bruschi, P. Buratti, G. Cenacchi, R. Coelho, F. Crisanti, B. Esposito, L. Gabellieri, F. Gandini, G. Granucci, E. Lazzaro, H. Krogler, S. Nowak, D. Pacella, L. Panaccione, G. Ramponi, A. Simonetto, C. Sozzi, O. Tudisco, M. Zerbini, F. Alladio, B. Angelini, M. L. Apicella, G. Apruzzese, E. Barbato, A. Bertocchi, M. Borra, G. Buceti, A. Cardinali, C. Centioli, R. Cesario, P. Chuilon, S. Ciattaglia, V. Cocilovo, R. De Angelis, D. Frigione, G. Gatti, E. Giovannozzi, M. Grolli, F. Iannone, M. Leigheb, G. Maddaluno, M. Marinucci, G. Mazzitelli, P. Micozzi, P. Orsitto, M. Panella, V. Pericoli, L. Pieroni, S. Podda, G. B. Righetti, F. Romanelli, S. E. Segre, S. Sternini, N. Tartoni, A. A. Tuccillo, V. Vitale, G. Vlad, V. Zanza, and F. Zonca, Plasma Phys. Controlled Fusion 41, B351 (1999). 
${ }^{7}$ C. Angioni, T. P. Goodman, M. A. Henderson, and O. Sauter, Nucl. Fusion 43, 455 (2003).

${ }^{8}$ T. P. Goodman, F. Felici, O. Sauter, J. P. Graves, and TCV Team, Phys. Rev. Lett. 106, 245002 (2011).

${ }^{9}$ M. Lauret, F. Felici, G. Witvoet, T. P. Goodman, G. Vandersteen, O. Sauter, M. R. de Baar, and TCV team, Nucl. Fusion 52, 62002 (2012).

${ }^{10}$ P. Buratti, E. Alessi, L. Amicucci, B. Angelini, M. L. Apicella, G. Apruzzese, G. Artaserse, E. Barbato, F. Belli, A. Bertocchi, W. Bin, L. Boncagni, A. Botrugno, S. Briguglio, A. Bruschi, G. Calabrò, A. Cardinali, C. Castaldo, S. Ceccuzzi, C. Centioli, R. Cesario, C. Cianfarani, S. Cirant, F. Crisanti, O. D’Arcangelo, M. De Angeli, R. De Angelis, L. Di Matteo, C. Di Troia, B. Esposito, D. Farina, L. Figini, G. Fogaccia, D. Frigione, V. Fusco, L. Gabellieri, C. Galperti, S. Garavaglia, E. Giovannozzi, G. Granucci, G. Grossetti, G. Grosso, Z. O. Guimarães-Filho, F. Iannone, A. Krivska, H. Kroegler, E. Lazzaro, M. Lontano, G. Maddaluno, C. Marchetto, M. Marinucci, D.
Marocco, G. Mazzitelli, C. Mazzotta, A. Milovanov, D. Minelli, F. C. Mirizzi, G. A. Moro, F. Napoli, S. Nowak, F. P. Orsitto, D. Pacella, L. Panaccione, M. Panella, V. Pericoli-Ridolfini, S. Podda, A. Pizzuto, G. Pucella, G. Ramogida, G. Ravera, A. Romano, C. Sozzi, A. A Tuccillo, O. Tudisco, B. Viola, V. Vitale, G. Vlad, V. Zanza, M. Zerbini, F. Zonca, M. Aquilini, P. Cefali, E. Di Ferdinando, S. Di Giovenale, G. Giacomi, F. Gravanti, A. Grosso, V. Mellera, M. Mezzacappa, A. Pensa, P. Petrolini, V. Piergotti, B. Raspante, G. Rocchi, A. Sibio, B. Tilia, C. Torelli, R. Tulli, M. Vellucci, and D. Zannetti, Nucl. Fusion 53, 104012 (2013).

${ }^{11}$ F. Porcelli, D. Boucher, and M. N. Rosenbluth, Plasma Phys. Controlled Fusion 38, 2163 (1996).

${ }^{12}$ B. Wan, J. Li, H. Guo, Y. Liang, G. Xu, L. Wang, and X. Gong, Nucl. Fusion 55, 104015 (2015).

${ }^{13}$ Z. Luo, B. Xiao, Y. Zhu, and F. Yang, Plasma Sci. Technol. 12, 412 (2010). 